\title{
Multi-colony tracking reveals spatio-temporal variation in carry-over effects between breeding success and winter movements in a pelagic seabird
}

\author{
Maria I. Bogdanova ${ }^{1, *}$, Adam Butler ${ }^{2}$, Sarah Wanless ${ }^{1}$, Børge Moe $^{3}$, \\ Tycho Anker-Nilssen ${ }^{3}$, Morten Frederiksen ${ }^{4}$, Thierry Boulinier ${ }^{5}$, Lorraine S. Chivers ${ }^{6}$, \\ Signe Christensen-Dalsgaard ${ }^{3}$, Sébastien Descamps ${ }^{7}$, Michael P. Harris ${ }^{1}$, \\ Mark Newell ${ }^{1}$, Bergur Olsen ${ }^{8}$, Richard A. Phillips ${ }^{9}$, Deryk Shaw ${ }^{10}$, Harald Steen ${ }^{7}$, \\ Hallvard Strøm ${ }^{7}$, Thorkell L. Thórarinsson ${ }^{11}$, Francis Daunt ${ }^{1}$ \\ ${ }^{1}$ Centre for Ecology \& Hydrology, Bush Estate, Penicuik EH26 0QB, UK \\ ${ }^{2}$ Biomathematics \& Statistics Scotland, The King's Buildings, Edinburgh EH9 3FD, UK \\ ${ }^{3}$ Norwegian Institute for Nature Research, 7485 Trondheim, Norway \\ ${ }^{4}$ Department of Bioscience, Aarhus University, 4000 Roskilde, Denmark \\ ${ }^{5}$ Centre d'Ecologie Fonctionnelle et Evolutive, UMR 5175 CNRS-Université Montpellier, 34293 Montpellier, France \\ ${ }^{6}$ Brundall, Norfolk NR13 5SD, UK \\ ${ }^{7}$ Norwegian Polar Institute, Fram Centre, 9296 Tromsø, Norway \\ ${ }^{8}$ Faroe Marine Research Institute, Noatun, 100 Torshavn, Faroe Islands \\ ${ }^{9}$ British Antarctic Survey, Natural Environment Research Council, Cambridge CB3 0ET, UK \\ ${ }^{10}$ Burkle, Fair Isle, Shetland ZE2 9JU, UK \\ ${ }^{11}$ Northeast Iceland Nature Research Centre, 640 Húsavík, Iceland
}

\begin{abstract}
Carry-over effects, whereby events in one season have consequences in subsequent seasons, have important demographic implications. Although most studies examine carry-over effects across 2 seasons in single populations, the effects may persist beyond the following season and vary across a species' range. To assess potential carry-over effects across the annual cycle and among populations, we deployed geolocation loggers on black-legged kittiwakes Rissa tridactyla at 10 colonies in the north-east Atlantic and examined relationships between the timing and destination of migratory movements and breeding success in the year of deployment and subsequent season. Both successful and unsuccessful breeders wintered primarily in the north-west Atlantic. Breeding success affected the timing of migration, whereby unsuccessful breeders departed the colony earlier, arrived at the post-breeding and main wintering areas sooner, and departed later the following spring. However, these patterns were only apparent in colonies in the south-west of the study region. Furthermore, the effect of breeding success was stronger on migration timing in the first part of the winter than later. Timing of migratory movements was weakly linked to subsequent breeding success, and there was no detectable association between breeding success in the 2 seasons. Our results indicate temporal structure and spatial heterogeneity in the strength of seasonal interactions among kittiwakes breeding in the north-east Atlantic. Variable fitness consequences for individuals from different colonies could have important implications for population processes across the species' range and suggest that the spatiotemporal dynamics of carry-over effects warrant further study.
\end{abstract}

KEY WORDS: Seasonal interactions · Migration · Reproduction ' Life-history strategies · Geolocation · Black-legged kittiwake $\cdot$ Rissa tridactyla $\cdot$ North Atlantic

${ }^{*}$ Corresponding author: marib@ceh.ac.uk

${ }^{\S}$ Advance View was available online May 11, 2017
(C) The authors 2017. Open Access under Creative Commons by Attribution Licence. Use, distribution and reproduction are unrestricted. Authors and original publication must be credited. 


\section{INTRODUCTION}

Understanding the fitness consequences of lifehistory decisions is fundamental to the study of population ecology (Stearns 1992). These decisions may impact on fitness immediately or affect subsequent life-history stages (Lindström 1999, Metcalfe \& Monaghan 2001). Among potentially important downstream fitness consequences are seasonal carry-over effects, whereby processes in one season have consequences in subsequent seasons (Norris \& Marra 2007, Harrison et al. 2011). Carry-over effects have been demonstrated in a wide array of taxa, including insects, amphibians, fish and mammals (reviewed by Harrison et al. 2011). Much of the research on carryover effects has been undertaken on birds, where studies initially focussed on the effect of winter ecology on subsequent breeding performance, based primarily on stable isotope signatures in feathers grown in winter. Widespread evidence now indicates that diet and habitat quality in winter are linked to key breeding parameters such as timing of arrival at breeding grounds and reproductive success, mediated by body condition during migration (Marra et al. 1998, Bearhop et al. 2004, Norris et al. 2004, Sorensen et al. 2009). More recently, studies have investigated links between breeding performance and migration in the subsequent winter using a range of methods, including field readable rings and miniaturised data loggers (Inger et al. 2010, Bogdanova et al. 2011, Latta et al. 2016). These studies demonstrated strong seasonal interactions in line with theoretical models of the costs of reproduction (Ylönen et al. 1998), such that reproductive success is linked to timing of departure on migration and non-breeding location and habitat quality. Overall, these studies suggest that carry-over effects may have profound repercussions for future fitness and population dynamics (Norris \& Marra 2007, Harrison et al. 2011).

The majority of studies of carryover effects have considered associations between 2 seasons. However, decisions or conditions experienced during the winter may affect perform- ance not just in the subsequent summer but also in the following winter and beyond; similarly, the costs of reproduction in summer may extend beyond the following winter into subsequent seasons (Senner et al. 2014; Fig. 1). Accordingly, a growing number of studies have tested seasonal interactions at longer temporal scales than the traditional 2-season comparison (Inger et al. 2010, Hoye et al. 2012, Senner et al. 2014, Latta et al. 2016). A second limitation of existing research is that studies have typically focussed on single populations, yet seasonal interactions may vary across a species' range (Fig. 1). For example, differences in local environmental conditions during the summer may lead to variable downstream effects on characteristics such as timing of migration, with carry-over effects potentially weaker when conditions are more favourable (Legagneux et al. 2012, Harrison et al. 2013). Alternatively, if differ-
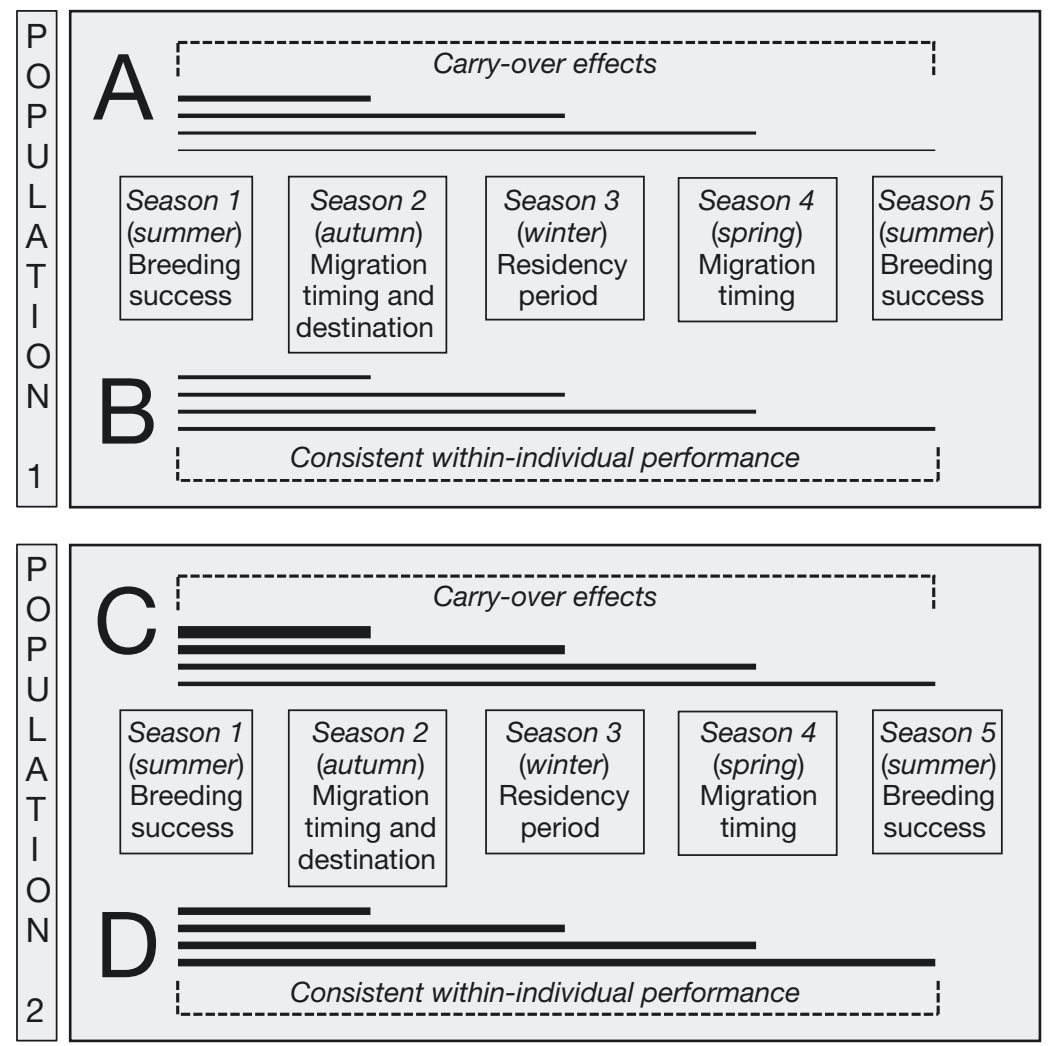

Fig. 1. Temporal structure and spatial variation in seasonal interactions. Temporal structure (illustrated as links between summer breeding success and subsequent seasons from autumn to the following summer) in Population 1 may exist, whereby seasonal interactions (A) weaken over time, evidence for 'true' carry-over effects (width of line denoting strength of link) or (B) are stable over time as a result of consistent within-individual performance. Spatial variation may exist whereby strength of seasonal interactions varies between populations: (C) carry-over effects are stronger in Population 2 (vs. A); similarly, (D) seasonal interactions resulting from consistent within-individual performance are more pronounced in Population 2 (vs. B) 
ent populations have common wintering grounds, individuals may adjust their migration schedules to reach the wintering grounds at the same time in order to maximise survival probability. Such variation in timing could shape the strength of carry-over effects across a species' range, with potentially major consequences for meta-population dynamics (Norris \& Marra 2007, Harrison et al. 2011).

Studies that quantify seasonal interactions over longer periods than the traditional 2-season time scale in multiple populations can also contribute to the challenging question of whether such interactions arise because of genuine carry-over effects (Norris \& Marra 2007, Harrison et al. 2011) or because of cross-seasonal correlations due to stable within-individual performance in breeding and overwinter life-history decisions (Daunt et al. 2006, 2014, Harrison et al. 2011; Fig. 1). Quantifying the relative importance of extrinsic and intrinsic effects has proved challenging in correlative studies, since they are confounded (individuals may vary both in performance and environments experienced). Two approaches have been used to date to tease apart these effects: experimental manipulation in one season as a causal test of carry-over effects (Studds \& Marra 2005, Legagneux et al. 2012, Catry et al. 2013, Schultner et al. 2014) and longitudinal measurements in individuals across a range of environmental conditions whereby they act as their own controls (Daunt et al. 2014). Studies that investigate the temporal structure in the strength of seasonal interactions in multiple populations provide a third option. Specifically, effects that are found consistently across populations to be stronger on events in the adjacent season than in subsequent seasons would provide evidence for genuine carry-over effects, whereas a sustained relationship over time would suggest that intrinsic effects predominate (Fig. 1).

In this study, we used data spanning 1 full annual cycle (breeding season to subsequent breeding season) from 10 colonies of black-legged kittiwake Rissa tridactyla (hereafter 'kittiwake') across a $23^{\circ}$ latitudinal range and $45^{\circ}$ longitudinal range in the northeast Atlantic to test for spatio-temporal variation in carry-over effects between reproductive performance and migratory movements. Previous work has demonstrated significant links between reproductive performance, timing of autumn migration and winter destination at 1 colony in the region (Bogdanova et al. 2011). In addition, a multi-colony study of winter distribution reported marked variation in timing of migration yet strong winter admixing among individuals from different breeding populations (Frederik- sen et al. 2012), which could form the requisite conditions whereby strength of carry-over effects vary across a species' range.

Our study tested 3 specific hypotheses. First, we hypothesised that, across colonies, there would be an overall relationship between breeding success and scheduling and location of migration, such that unsuccessful individuals depart the colony earlier, migrate farther, reach their winter destinations sooner and spend longer at those destinations, in line with previous findings in this and other species (Summers et al. 1996, Phillips et al. 2005, 2007, Bogdanova et al. 2011). Second, we hypothesised that there would be spatial variation in the strength of carry-over effects among colonies, since variation in environmental conditions among colonies is likely, and more favourable conditions are predicted to dampen carry-over effects (Legagneux et al. 2012, Harrison et al. 2013). Third, we tested alternative hypotheses on the temporal structure of seasonal interactions: (1) relationships are stronger with the adjacent season than with subsequent seasons, representing evidence for true carry-over effects (Harrison et al. 2011); (2) relationships are sustained across time, representing evidence that intrinsic performance underpins seasonal interactions (Daunt et al. 2006).

\section{MATERIALS AND METHODS}

\section{Study sites and field data collection}

The study was undertaken on adult kittiwakes breeding at 10 colonies across the north-east Atlantic (Table 1, Fig. 2; and see Frederiksen et al. 2012). In the 2009 breeding season, individuals were captured at the nest site using noose poles and fitted with geolocation loggers (Mk13 British Antarctic Survey; $20 \times$ $9 \times 6.5 \mathrm{~mm}$; mass: $1.8 \mathrm{~g}$ ) attached to a plastic leg ring. Deployment methods and protocols were the same at all colonies, and handling time was typically less than 5 min. Breeding success was subsequently recorded for the tracked adults as the number of chicks fledged per nest or, at some colonies, the number of chicks alive at mid to late chick-rearing, a reliable indicator of number of chicks fledged (Lewis et al. 2001). Breeding success was unavailable for 1 of the colonies (Hafnarhólmi, Iceland). In 2010, the study individuals were recaptured, the loggers retrieved and breeding success recorded at all 10 colonies. Deployment and retrieval took place between mid-incubation and mid-chick-rearing, with the majority of captures occurring during early 
Table 1. Study colonies of black-legged kittiwakes Rissa tridactyla, number of geolocation loggers deployed (Depl.), number of individuals tracked successfully (Retr.: loggers retrieved), and those with known breeding success in both years, in 2009 only and in 2010 only

\begin{tabular}{|c|c|c|c|c|c|c|c|}
\hline \multirow{2}{*}{ Colony } & \multirow{2}{*}{ Lat. } & \multirow[t]{2}{*}{ Lon. } & \multirow[t]{2}{*}{ Depl. } & \multirow[t]{2}{*}{ Retr. } & \multicolumn{3}{|c|}{-Breeding success- } \\
\hline & & & & & $\begin{array}{c}2009 \& \\
2010\end{array}$ & 2009 & 2010 \\
\hline \multicolumn{8}{|l|}{ Norway } \\
\hline Grumant & $78^{\circ} 10^{\prime} \mathrm{N}$ & $15^{\circ} 09^{\prime} \mathrm{E}$ & 20 & 16 & 13 & 0 & 2 \\
\hline Bjørnøya & $74^{\circ} 23^{\prime} \mathrm{N}$ & $19^{\circ} 08^{\prime} \mathrm{E}$ & 20 & 15 & 5 & 8 & 0 \\
\hline Hornøya & $70^{\circ} 23^{\prime} \mathrm{N}$ & $31^{\circ} 09^{\prime} \mathrm{E}$ & 20 & 15 & 13 & 1 & 0 \\
\hline Anda & $69^{\circ} 04^{\prime} \mathrm{N}$ & $15^{\circ} 10^{\prime} \mathrm{E}$ & 20 & 12 & 10 & 2 & 0 \\
\hline Røst & $67^{\circ} 30^{\prime} \mathrm{N}$ & $12^{\circ} 05^{\prime} \mathrm{E}$ & 39 & 22 & 13 & 0 & 5 \\
\hline \multicolumn{8}{|l|}{ Iceland } \\
\hline Hafnarhólmi & $65^{\circ} 32^{\prime} \mathrm{N}$ & $13^{\circ} 45^{\prime} \mathrm{W}$ & 20 & 12 & 0 & 0 & 9 \\
\hline \multicolumn{8}{|l|}{ Faroe Islands } \\
\hline Stóra Dímun & $61^{\circ} 41^{\prime} \mathrm{N}$ & $06^{\circ} 45^{\prime} \mathrm{W}$ & 20 & 10 & 9 & 0 & 0 \\
\hline \multicolumn{8}{|l|}{ UK } \\
\hline Fair Isle & $59^{\circ} 32^{\prime} \mathrm{N}$ & $01^{\circ} 38^{\prime} \mathrm{W}$ & 18 & 15 & 15 & 0 & 0 \\
\hline Isle of May & $56^{\circ} 11^{\prime} \mathrm{N}$ & $02^{\circ} 33^{\prime} \mathrm{W}$ & 25 & 16 & 14 & 0 & 0 \\
\hline Rathlin & $55^{\circ} 29^{\prime} \mathrm{N}$ & $06^{\circ} 19^{\prime} \mathrm{W}$ & 18 & 5 & 5 & 0 & 0 \\
\hline Total & & & 220 & 138 & 97 & 11 & 16 \\
\hline
\end{tabular}

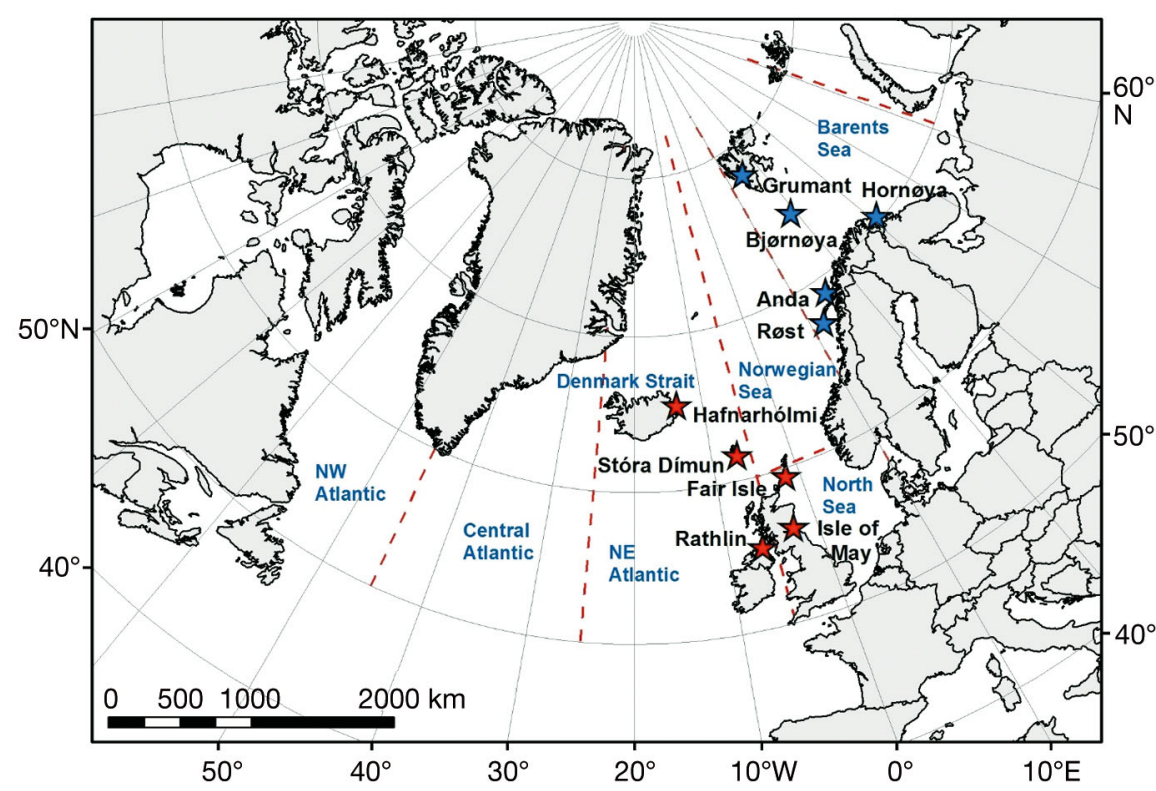

Fig. 2. Location of study colonies of black-legged kittiwakes Rissa tridactyla (blue stars: NE colonies, red stars: SW colonies); dashed red lines indicate the boundaries of wintering areas

chick-rearing. In total, 220 loggers were deployed in 2009,138 of these were retrieved in 2010, of which $124(89.9 \%)$ had breeding success data for 2009, 2010 or both years, $5(3.6 \%)$ were excluded because of logger malfunction, and $9(6.5 \%)$ were excluded because breeding success data were not available. Sample size of individuals that were tracked successfully and for which breeding success was known is shown in Table 1. The sex of a subset of the individuals was determined using molecular techniques
(Griffiths et al. 1996) or morphometric measurements (head-bill and wing length; Gasparini et al. 2002).

A previous study at 1 of these colonies (Isle of May National Nature Reserve, Scotland) found no negative impact of the loggers on breeding success or probability of returning to the colony in the following year (Bogdanova et al. 2011). We did not test for logger effects in the current study, but since field protocols at all colonies were the same as in the previous study, we have no reason to expect negative impacts of the devices.

\section{Data processing}

Light intensity data recorded by the geolocation loggers were processed to obtain the timing of sunrise and sunset. Best results were obtained with a threshold light intensity of 10 and a sun elevation angle of $-3^{\circ}$. For each day at local noon and midnight, latitude was estimated from day length and longitude from the timing of local noon/midnight in relation to UTC. Locations were excluded during $50^{\circ}$ the breeding season when there are frequent light interference events, and around the equinoxes (8 September to 20 October and 20 February to 3 April; Frederiksen et al. 2012), when latitude cannot be calculated reliably. In Arctic areas, it was not possible to obtain locations during the period of constant daylight in the summer. For example, at $66,70,74$ and $78^{\circ} \mathrm{N}$, the sun elevation angle is constantly above $-3^{\circ}$ for the periods 26 May to 18 July, 9 May to 5 August, 25 April to 19 August and 14 April to 30 August, respectively. The retained locations were smoothed to reduce the influence of outliers when calculating migration metrics. Full details of the data processing and calibration are provided by Frederiksen et al. (2012).

Migratory movements were identified based on visual examination of the location data in ArcGIS (v.10.1, ESRI) and were indicated by series of fixes in a consistent direction (average $[ \pm \mathrm{SE}]$ distance between adjacent fixes: $254 \pm 37 \mathrm{~km}$ ). In contrast, clus- 
ters of fixes lacking directional movement represented residency time within wintering areas (average distance between adjacent fixes: $99 \pm 5 \mathrm{~km}$ ). Outside the breeding season, individuals from the study colonies range widely across the North Atlantic and adjacent seas (North Sea, Norwegian Sea, Barents Sea and Labrador Sea; Bogdanova et al. 2011, Frederiksen et al. 2012). Wintering areas were defined as follows: the North Atlantic was split into 3 parts of approximately equal size (NW: $>45^{\circ} \mathrm{W}$; Central: 25-45 ${ }^{\circ} \mathrm{W}$; NE: $5-25^{\circ} \mathrm{W}$; following Bogdanova et al. 2011); the remaining areas were geographically defined seas (North Sea, Norwegian Sea and Barents Sea; Fig. 2). For each individual, all areas visited outside the breeding season were identified using an automated procedure whereby each location in the dataset was assigned an identity based on the wintering area within which it was positioned. The identity and number of areas visited varied among individuals both among and within colonies. Individuals were considered to visit an area if they spent more than $3 \mathrm{~d}$ therein; if visits lasted $3 \mathrm{~d}$ or less, the individual was considered to be in transit.

The following metrics of timing of migration were extracted from the location data: for autumn migration: (1) date of departure from the vicinity of the colony (defined as the area within the average location error of $180 \mathrm{~km}$ from the colony, Phillips et al. 2004), (2) date of arrival at the post-breeding area (defined as the area visited immediately after breeding) and (3) date of arrival at the main wintering area (defined as the area where the individual spent the most time in winter); for spring migration: (1) date of departure from the main wintering area and (2) date of arrival in the vicinity of the colony. There was no evidence that individuals used a pre-breeding area after the spring migration equivalent to the postbreeding area visited prior to the autumn migration (see 'Results: Effects of breeding success and colony location on subsequent migratory movements'). In contrast to a previous year at the Isle of May, where $42 \%$ of individuals undertook a pre-breeding excursion to the central Atlantic (Bogdanova et al. 2011), 11 individuals from 3 colonies in this study (Rathlin, Northern Ireland; Fair Isle, Scotland; Stóra Dímun, Faroe Islands) undertook an excursion at this time, representing just $9 \%$ of tracked individuals. Moreover, the destinations of these movements were closer and more variable than those recorded for Isle of May individuals in the previous study, so we did not consider them further here. As movements from the study colonies typically involved an east-west component, the timing of migratory movements occur- ring during the autumn or spring equinox could generally be extracted using longitude only. In the 3 colonies with the highest latitudes $\left(>70^{\circ} \mathrm{N}\right.$; Hornøya, mainland Norway; Grumant and Bjørnøya, Svalbard Archipelago, Norway), dates of departure from the colony at the end of the breeding season and arrival at the post-breeding area could not be determined as they coincided with the summer period of constant daylight. Furthermore, some individuals migrated directly to the main wintering area. In addition, 1 individual from Anda (mainland Norway) and 2 individuals from Rathlin stayed in the vicinity of the colony throughout the winter. Thus, migration metrics were not available for all individuals at all colonies (sample sizes in each analysis are shown in Table 2). For each individual, winter residency period was the total amount of time (number of days) spent within the main wintering area. Presence in this area during the equinox periods could be established from longitude.

\section{Effects of breeding success and colony location on subsequent migratory movements}

Effects of breeding success and colony location on the timing of subsequent migratory movements and winter residency period were investigated using linear mixed models $(\mathrm{n}=108$ individuals from 9 colonies). Response variables were (1) date of departure from the vicinity of the colony, (2) date of arrival at the post-breeding area, (3) date of arrival at the main wintering area, (4) winter residency period, (5) date of departure from the main wintering area and (6) date of arrival in the vicinity of the colony. Fixed effects were breeding success in 2009, colony latitude and longitude, and the random effect was colony identity. We adopted the same approach as Bogdanova et al. (2011) in modelling breeding success as a binary variable (successful, i.e. raised at least 1 chick, vs. unsuccessful, i.e. raised no chicks), since the majority of successful kittiwakes raised 1 chick (63\% in 2009 and $76 \%$ in 2010). Previous work has shown differences between the sexes in carryover effects (Bogdanova et al. 2011, Schultner et al. 2014). However, we could not include sex in the models, as the sample size of sexed individuals was not sufficient to simultaneously test for potential effects of this variable and of breeding success and colony location. However, there was no evidence that breeding success and sex were confounded, as the distribution of males and females among successful and unsuccessful breeders was well-balanced (suc- 
cessful: $47 \%$ males, $53 \%$ females; unsuccessful: $43 \%$ males, $57 \%$ females). The simplest ('null') model contained only a random effect for 'colony' but no fixed effects. The most complex ('full') model contained 'colony' as a random effect, the 3 fixed effects and all interactions. Since the study colonies are distributed in a south-west to north-east direction, evidence for a colony latitude by longitude interaction can be interpreted as an effect of colony location (Fig. 2). In contrast, main effects of latitude and longitude represent north-south and east-west patterns among colonies, respectively. We considered all possible subsets of the variables in the full model, which led to a candidate set containing 19 models.

For the purposes of model comparison, models were fitted using maximum likelihood as they had different fixed effects but the same random structure (Zuur et al. 2009). Support for different candidate models was assessed using Akaike's information criterion adjusted for small sample size (AICc). The model with the lowest AICc value was considered best supported. Models were deemed strongly supported if they differed from the best model by less than 2 AICc units (Burnham \& Anderson 2002), unless they were otherwise identical to the best model but contained 1 more parameter, in which case this rule of thumb is not appropriate (Burnham \& Anderson 2002) and the more complex models were disregarded on the grounds of parsimony. The final model was re-fitted using restricted maximum likelihood to obtain more unbiased parameter estimates and their standard errors (Zuur et al. 2009). Marginal coefficient of determination $\left(\mathrm{R}_{\mathrm{m}}^{2}\right.$ representing the variance explained by the fixed effects) and conditional coefficient of determination $\left(\mathrm{R}_{\mathrm{c}}^{2}\right.$ representing the variance explained by both fixed and random effects; Nakagawa \& Schielzeth 2013) were calculated for the best model in each candidate set. Analyses were performed in R (R Core Team 2015; packages nlme, Pinheiro et al. 2016; and MuMIn, Bartoń 2015).

\section{Effects of previous breeding success, timing of migration and winter residency period on subsequent breeding success}

Effects of previous breeding success (in 2009), timing of migratory movements and winter residency period on subsequent breeding success (in 2010) were investigated using generalised linear mixed models with binomial error structure $(\mathrm{n}=113$ individuals from 10 colonies). The response variable was breeding success in 2010, the random effect was colony identity, and potential explanatory variables were (1) breeding success in the previous year (2009), (2) date of departure from the vicinity of the colony, (3) date of arrival at the post-breeding area, (4) date of arrival at the main wintering area, (5) winter residency period, (6) date of departure from the main wintering area and (7) date of arrival in the vicinity of the colony. Due to varying sample sizes for the different explanatory variables (see 'Data processing') and collinearity between some of the timing variables, it was not feasible to consider all of these simultaneously within model selection. Therefore, initial exploratory analyses were carried out, testing separately for relationships between each of the explanatory variables and breeding success in 2010 by comparing the model containing the respective explanatory variable with the intercept-only model. Only variables that were potentially associated with subsequent breeding success based on the initial analysis (whose inclusion resulted in a lower AICc value compared to the intercept-only model) were considered for inclusion in the full model. The 'null' model contained colony identity as a random effect but no covariates. A 'full model' was then constructed, based upon the explanatory variables that were found to be important in the initial exploratory analyses. All subsets of the variables in this full model were then considered, with model selection and assessment of model goodness-of-fit carried out as described in the analysis of effects of breeding success on subsequent winter movements (see previous section). Analyses were performed in $\mathrm{R}$ (packages lme4, Bates et al. 2015; and MuMIn, Bartoń 2015).

\section{Winter distribution in relation to previous and subsequent breeding success}

For each colony, we examined the relationships between breeding success in 2009 and 2010 and atsea distribution in the intervening non-breeding season. This involved calculating the kernel density of locations of successful and unsuccessful breeders in each month from the time of departure from the vicinity of the colony in late summer, to return in the following spring. Kernel density was calculated in the $\mathrm{R}$ package adehabitatHR (Calenge 2006), with a smoothing parameter $h$ of $180 \mathrm{~km}$, corresponding to the average error of the location data (Phillips et al. 2004). Core areas (50\% kernel contour) were plotted in a Lambert azimuthal equal-area projection. To quantify variation in monthly non-breeding distribution linked to breeding success in 2009 and in 2010, we estimated the similarity between the utilisation 
distributions of successful and unsuccessful breeders within the core areas using Bhattacharyya's affinity measure (Fieberg \& Kochanny 2005). This measure ranges from 0 (no overlap) to 1 (identical distributions). To test whether the observed similarity in distributions between the 2 groups of breeders deviated from that expected by chance, we used a permutation test, where for each colony, we fixed the number of successful and unsuccessful individuals to be the same as in the observed data but randomised the allocation of breeding success to individuals. The permutation test was run for 1000 iterations and the median, 2.5 and 97.5 percentile values for Bhattacharyya's affinity measure over these iterations were extracted: observed values outside these boundaries would indicate a significant difference from random at a $5 \%$ significance level. Here, we were particularly interested in detecting levels of similarity that were lower than expected by chance (which would be shown by an observed value below the 2.5 percentile). In both 2009 and 2010, at some colonies, all study individuals bred successfully or unsuccessfully, precluding a comparison of the utilisation distributions in these cases.

The study colonies formed 2 well-defined geographic clusters: UK, Faroese and Icelandic (Rathlin, Isle of May, Fair Isle, Stóra Dimun, Hafnarhólmi) in the south-west of the region, hereafter referred to as SW colonies, and Norwegian (Røst, Anda, Hornøya, Bjørnøya, Grumant) in the north-east of the region, hereafter referred to as NE colonies (Fig. 2). The results are presented by colony cluster to aid descriptions of geographic patterns, but clusters were not used in the analyses.

\section{RESULTS}

\section{Effects of breeding success and colony location on subsequent migratory movements}

Breeding success was moderately high in 2009, with $72 \%$ of tracked individuals raising at least 1 chick. After leaving the vicinity of the colony, 33\% of kittiwakes from the SW colonies moved to a postbreeding area in the Denmark Strait, 25\% moved to other areas (North Sea, Irish Sea, central Atlantic), and $37 \%$ travelled directly to the main wintering area in the north-west Atlantic (Fig. 3); the remaining $5 \%$ of individuals remained in the vicinity of the colony. In contrast, most individuals (72\%) from the NE colonies initially moved to a post-breeding area in the Barents Sea (Fig. 3), 12\% moved to the postbreeding area in the Denmark Strait, $9 \%$ migrated to other areas (Norwegian Sea, North Sea, central Atlantic), 5\% moved directly to the north-west Atlantic and $2 \%$ remained close to the colony.

Date of departure from the vicinity of the colony was related to colony location (as indicated by the interaction of colony latitude by longitude) and breeding success (Table 2). Kittiwakes in SW colonies left earlier than those in NE colonies and, across colonies, unsuccessful breeders departed earlier than their successful counterparts (Fig. 4a). There was 1 model within 2 AICc units of the best model (excluding those with 1 extra parameter, see 'Materials and methods'), containing the 3 main effects (breeding success, latitude and longitude) but no interaction term (see Table S1a in the Supplement at www.intres.com/articles/suppl/m578p167_supp.pdf). Date of

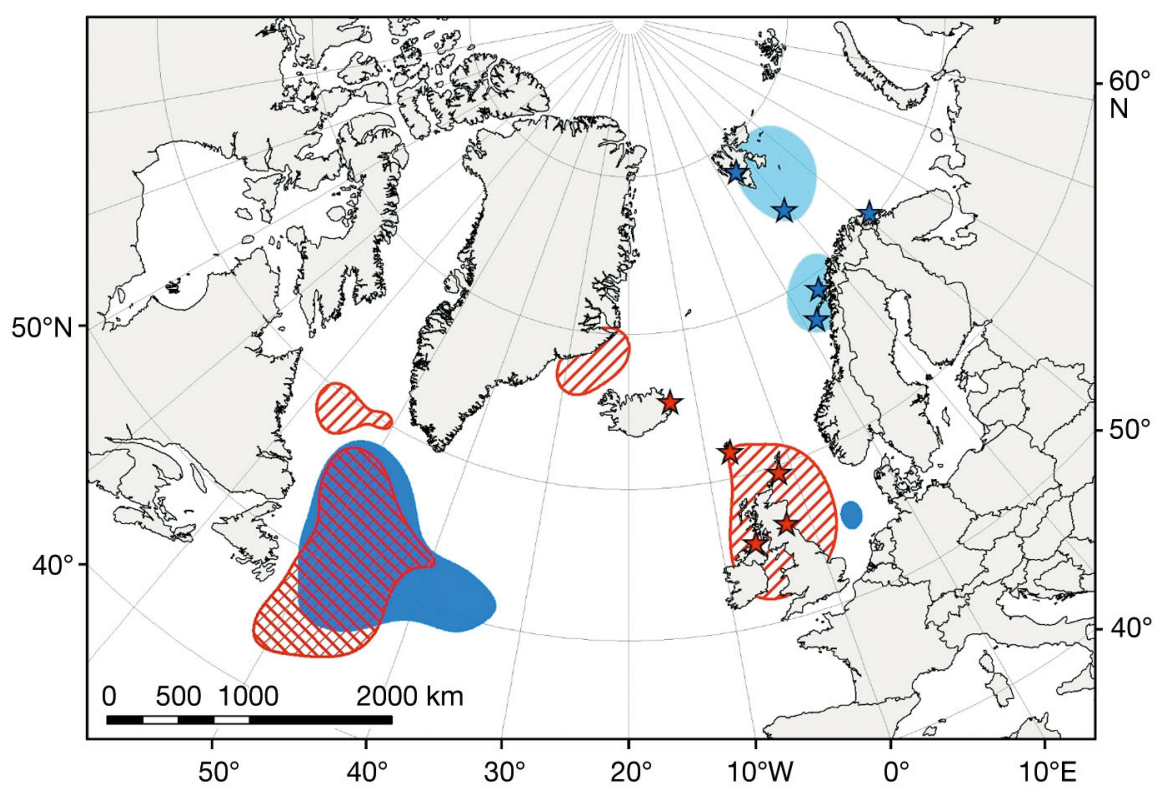

Fig. 3. Core areas (50\% density kernel contours) within the post-breeding area (August to September; light blue: NE colonies, single red hatching: SW colonies), and within the main wintering area of black-legged kittiwakes Rissa tridactyla (December; dark blue: NE colonies, red cross hatching: SW colonies). NE colonies shown with blue stars; SW colonies shown with red stars 
Table 2. Linear mixed models testing for relationships between breeding success of black-legged kittiwakes Rissa tridactyla in 2009 (BS), colony latitude and longitude, and timing of subsequent migratory movements or winter residency period. Only the best model for each migration metric is presented. For the full set of candidate models, their AICc values and Akaike weights see Table S1 in the Supplement at www.int.res.com/articles/suppl/m578p167_supp.pdf. $\mathrm{R}_{\mathrm{m}}^{2}$ : marginal coefficient of determination (representing the variance explained by the fixed effects) $\mathrm{R}_{\mathrm{c}}^{2}$ : conditional coefficient of determination (representing the variance explained by both fixed and random effects, see 'Materials and methods' for details)

\begin{tabular}{|c|c|c|c|c|c|c|c|c|c|c|c|}
\hline \multirow{2}{*}{ Migration metric } & \multirow{2}{*}{$\begin{array}{l}\mathrm{N} \text { indi- } \\
\text { viduals }\end{array}$} & \multirow{2}{*}{$\begin{array}{c}\mathrm{N} \text { para- } \\
\text { meters }\end{array}$} & \multicolumn{7}{|c|}{ _ Parameter estimate (standard error) } & \multirow{2}{*}{$\mathrm{R}_{\mathrm{m}}^{2}$} & \multirow{2}{*}{$\mathrm{R}_{\mathrm{c}}^{2}$} \\
\hline & & & BS & Lat & Lon & BS:Lat & BS:Lon & Lat:Lon & BS:Lat:Lon & & \\
\hline Departure from colony area & 54 & 6 & $\begin{array}{c}18.11 \\
(12.63)\end{array}$ & $\begin{array}{c}-6.98 \\
(1.88)\end{array}$ & $\begin{array}{c}-41.00 \\
(27.54)\end{array}$ & & & $\begin{array}{c}0.67 \\
(0.41)\end{array}$ & & 0.40 & 0.44 \\
\hline Arrival at post-breeding area & 47 & 7 & $\begin{array}{c}-4895.64 \\
(1440.47)\end{array}$ & $\begin{array}{c}-88.74 \\
(23.76)\end{array}$ & $\begin{array}{c}52.68 \\
(14.78)\end{array}$ & $\begin{array}{c}81.52 \\
(23.85)\end{array}$ & $\begin{array}{c}-49.47 \\
(14.84)\end{array}$ & & & 0.45 & 0.45 \\
\hline Arrival at main wintering area & 84 & 9 & $\begin{array}{c}-299.00 \\
(193.20)\end{array}$ & $\begin{array}{l}-7.11 \\
(4.05)\end{array}$ & $\begin{array}{c}-68.17 \\
(25.46)\end{array}$ & $\begin{array}{c}5.22 \\
(3.11)\end{array}$ & $\begin{array}{c}37.00 \\
(19.42)\end{array}$ & $\begin{array}{c}1.03 \\
(0.38)\end{array}$ & $\begin{array}{c}-0.55 \\
(0.29)\end{array}$ & 0.23 & 0.60 \\
\hline Winter residency period & 108 & 9 & $\begin{array}{c}0.06 \\
(196.58)\end{array}$ & $\begin{array}{c}4.03 \\
(4.35)\end{array}$ & $\begin{array}{l}52.46 \\
(28.03)\end{array}$ & $\begin{array}{c}-0.74 \\
(3.26)\end{array}$ & $\begin{array}{c}-31.73 \\
(21.93)\end{array}$ & $\begin{array}{c}-0.82 \\
(0.42)\end{array}$ & $\begin{array}{c}0.49 \\
(0.33)\end{array}$ & 0.20 & 0.51 \\
\hline Departure from main wintering area & 84 & 7 & $\begin{array}{r}-224.71 \\
(60.59)\end{array}$ & $\begin{array}{c}-3.59 \\
(1.13)\end{array}$ & $\begin{array}{r}-30.26 \\
(5.88)\end{array}$ & $\begin{array}{c}3.45 \\
(0.92)\end{array}$ & & $\begin{array}{c}0.44 \\
(0.09)\end{array}$ & & 0.32 & 0.32 \\
\hline Arrival in colony area & 98 & 5 & & $\begin{array}{l}-2.36 \\
(0.98)\end{array}$ & $\begin{array}{r}-40.16 \\
(6.08)\end{array}$ & & & $\begin{array}{c}0.59 \\
(0.09)\end{array}$ & & 0.66 & 0.77 \\
\hline
\end{tabular}

arrival at the post-breeding area was related to an interaction between colony location and breeding success (Table 2). Among individuals from SW colonies, unsuccessful breeders arrived earlier than successful ones, whereas among individuals from NE colonies, date of arrival was unaffected by breeding status (Fig. 4b). Date of arrival at the main wintering area was also affected by a similar interaction between colony location and breeding success (Table 2): unsuccessful breeders from SW colonies arrived earlier than successful indi-

Fig. 4. Timing of migratory movements of black-legged kittiwakes Rissa tridactyla and winter residency period in 2009/2010 winter in relation to breeding success in 2009 and colony location: (a) date of departure from the colony area; (b) date of arrival at the post-breeding area; (c) date of arrival at the main wintering area; (d) winter residency period; (e) date of departure from the main wintering area; and (f) date of arrival in the colony area for unsuccessful (grey bars) and successful (white bars) individuals from NE and SW colonies. Days of the year run from 1 January 2009 ; values are mean $\pm \mathrm{SE}$; sample sizes of individuals are shown above the bars
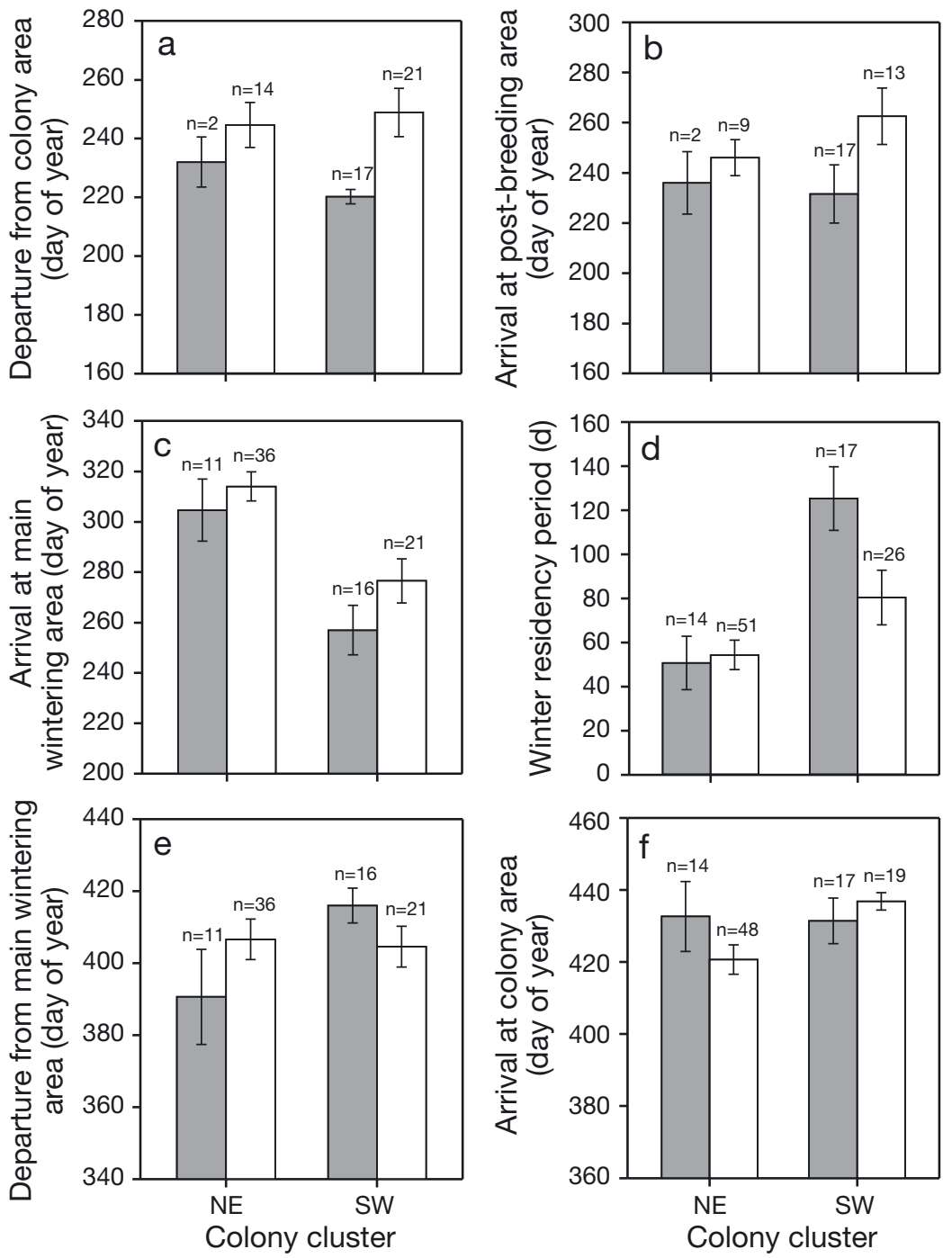
viduals, whereas arrival dates of successful and unsuccessful individuals from NE colonies were similar (Fig. 4c). There were 4 models within 2 AICc units of the best model, all of which contained colony latitude, longitude and their interaction, suggesting a strong effect of colony location (Table S1c).

Winter residency period in the north-west Atlantic was also influenced by interactive effects of breeding success and colony location (Table 2). Unsuccessful kittiwakes from SW colonies spent longer in the main wintering area than successful breeders, whereas among individuals from NE colonies, the time spent in this area was similar in the 2 groups (Fig. 4d). There were 2 models within 2 AICc units of the best model, both containing colony latitude, longitude and the interaction between them (Table S1d).

Date of departure from the north-west Atlantic was also related to an interaction between breeding success and colony location (Table 2). Unsuccessful breeders from SW colonies departed later than successful individuals, whereas they tended to depart earlier among tracked individuals from NE colonies (Fig. 4e). Date of arrival in the vicinity of the colony at the end of the winter was related to colony location only (Table 2); individuals from SW colonies returned later than individuals from NE colonies (Fig. 4f).

Overall, the effects of breeding success and colony location on subsequent migration strategy were strong, but gradually weakened over the course of the winter (evident in the $\mathrm{R}^{2} \mathrm{~m}$ values in Table 2), to the point that prior breeding success was not included in the final model explaining date of arrival in the vicinity of the colony in the subsequent season (Table 2).

\section{Effects of previous breeding success, timing of migration and winter residency period on subsequent breeding success}

Breeding success in 2010 was lower than in 2009, with $55 \%$ of tracked individuals successfully raising at least 1 chick. Breeding success was most related to colony identity (as evident from the $\mathrm{R}_{\mathrm{m}}^{2}$ and $\mathrm{R}_{\mathrm{c}}^{2}$ values in Table 3). In addition, there was weak evidence that unsuccessful breeders in 2010 had arrived at the main wintering area in the NW Atlantic earlier, and had departed later in the previous winter (Tables 3 \& 4). Breeding success in 2010 was not related to date of departure from the vicinity of the colony, date of arrival in the post-breeding area in 2009 or date of arrival in the vicinity of the colony in the spring 2010, and we found no effect of breeding success in 2009 on breeding success in 2010 (Table S2).

\begin{tabular}{|c|c|c|c|c|c|c|c|}
\hline Model & $\begin{array}{l}\text { No. of } \\
\text { para- } \\
\text { meters }\end{array}$ & $\mathrm{AICc}$ & $\begin{array}{l}\mathrm{AICc} \\
\text { weight }\end{array}$ & $\mathrm{R}_{\mathrm{m}}^{2}$ & $\mathrm{R}_{\mathrm{c}}^{2}$ & $\begin{array}{l}\text { Para- } \\
\text { meter }\end{array}$ & $\begin{array}{l}\text { Estimate } \\
\quad \pm \mathrm{SE}\end{array}$ \\
\hline $\mathrm{TA}+\mathrm{TD}+\mathrm{TA} \times \mathrm{TD}$ & 5 & 83.2 & 0.25 & 0.07 & 0.76 & $\begin{array}{c}\mathrm{TA} \times \mathrm{TD} \\
\mathrm{TA} \\
\mathrm{TD} \\
\text { Intercept }\end{array}$ & $\begin{aligned}-0.019 & \pm 0.021 \\
0.094 & \pm 0.086 \\
-0.074 & \pm 0.066 \\
-0.325 & \pm 0.271\end{aligned}$ \\
\hline $\mathbf{T A}+\mathbf{T D}$ & 4 & 82.9 & 0.28 & 0.07 & 0.73 & $\begin{array}{c}\text { TA } \\
\text { TD } \\
\text { Intercept }\end{array}$ & $\begin{aligned} 0.014 & \pm 0.009 \\
-0.013 & \pm 0.010 \\
-0.079 & \pm 0.052\end{aligned}$ \\
\hline TA & 3 & 83.2 & 0.24 & 0.05 & 0.70 & $\begin{array}{c}\mathrm{TA} \\
\text { Intercept }\end{array}$ & $\begin{array}{r}0.015 \pm 0.009 \\
-0.028 \pm 0.028\end{array}$ \\
\hline $\mathrm{TD}$ & 3 & 84.3 & 0.14 & 0.02 & 0.71 & $\begin{array}{c}\text { TD } \\
\text { Intercept }\end{array}$ & $\begin{array}{l}-0.014 \pm 0.011 \\
-0.041 \pm 0.044\end{array}$ \\
\hline Intercept only & 2 & 85.1 & 0.09 & 0.00 & 0.67 & Intercept & $0.016 \pm 0.010$ \\
\hline
\end{tabular}

Table 3. Generalised linear mixed models testing for relationships between timing of key migratory movements of black-legged kittiwakes Rissa tridactyla during the previous non-breeding season and breeding success in 2010 ( $\mathrm{n}=92$ birds; TA: timing of arrival in the main wintering area; TD: timing of departure from the main wintering area). The best model is shown in bold; $\mathrm{R}_{\mathrm{m}}^{2}$ : marginal coefficient of determination (representing the variance explained by the fixed effects); $\mathrm{R}_{\mathrm{c}}^{2}$ : conditional coefficient of determination (representing the variance explained by both fixed and random effects, the latter being colony identity)

\section{Winter distribution in relation to previous and subsequent breeding success}

Comparison of the winter distribution of individuals in relation to their success in the previous breeding season (2009) was possible for 4 colonies (Grumant, Hornøya, Røst and Rathlin). At the remaining 5 colonies, all individuals were either successful or unsuccessful. Overlap in utilisation distributions (based on Bhattacharyya's affinity index; Fig. 5) of successful and unsuccessful individuals within the core areas was high in the late summer (August) when individuals were still 
Table 4. Percentage of unsuccessful and successful blacklegged kittiwake Rissa tridactyla breeders in 2010 in relation to date of arrival at the main wintering area and to date of departure from the main wintering area. For illustrative purposes, the timing of movements was split into 2 categories, early and late, based on median values. However, the statistical analysis was carried out with timing fitted as a continuous variable (see 'Materials and methods')

\begin{tabular}{|c|c|c|}
\hline & $\begin{array}{l}\text { Unsuccessful } \\
\text { in } 2010(\%)\end{array}$ & $\begin{array}{l}\text { Successful } \\
\text { in } 2010(\%)\end{array}$ \\
\hline \multicolumn{3}{|c|}{ Arrival at main wintering area } \\
\hline Early & 68 & 32 \\
\hline Late & 41 & 59 \\
\hline \multicolumn{3}{|c|}{ Departure from main wintering area } \\
\hline Early & 48 & 52 \\
\hline Late & 54 & 46 \\
\hline
\end{tabular}

in the vicinity of the colony (Fig. 5). Thereafter, overlap was moderate to low throughout the winter, with lower overlap generally observed during the main migration periods (Fig. 5). Overlap was again high in the following spring (April; Fig. 5) when kittiwakes

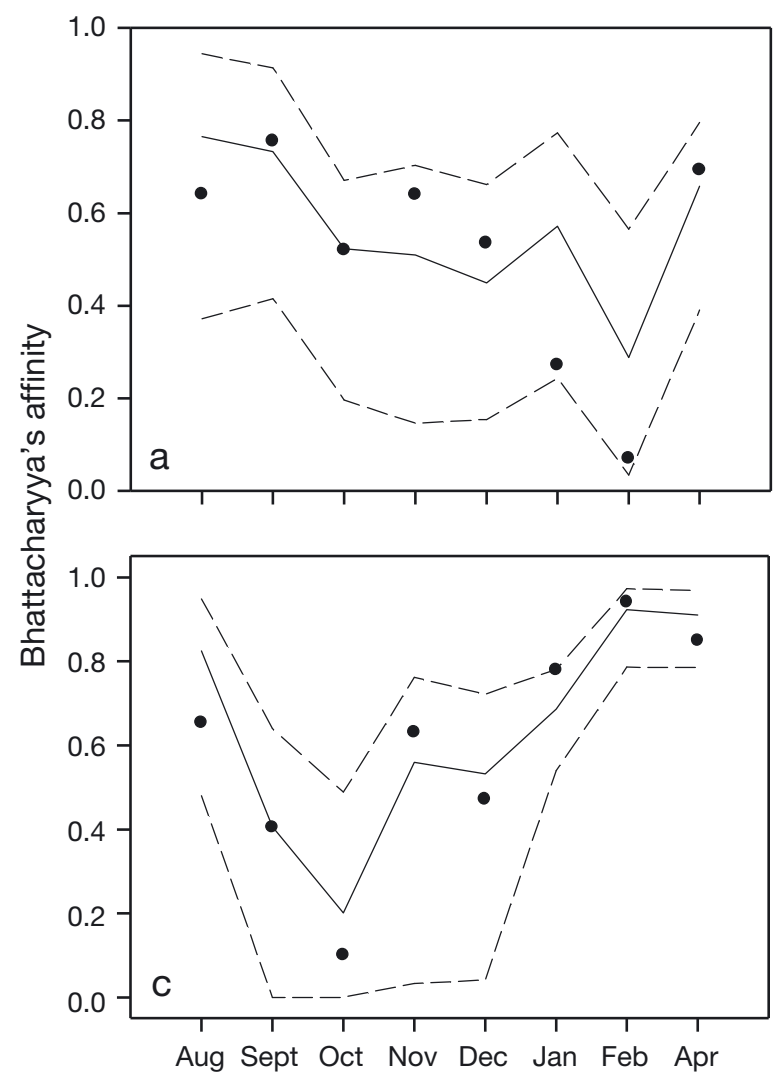

had returned to the vicinity of their breeding colonies. However, in none of the colonies did monthly overlap in distribution of successful and unsuccessful breeders deviate significantly from that expected by chance (Fig. 5; observed values inside the 2.5 and 97.5 percentile values).

Comparison of the winter distributions of individuals that were successful and unsuccessful in the subsequent breeding season (2010) was possible for 7 colonies (Anda, Grumant, Hornøya, Røst, Hafnarhólmi, Isle of May and Rathlin). At the remaining 3 colonies, breeding success was the same for all study individuals, precluding comparison between these 2 groups. Overlap in utilisation distributions of successful and unsuccessful individuals from the NE colonies within core areas was high in summer (August) and the following spring (April) when the individuals had returned to the vicinity of the colony. Overlap was moderate in September, falling to low or 0 in the rest of the winter (October to February), with the exception of Røst where overlap was high between November and February (Fig. 6d). A similar pattern to that in the NE colonies was observed in 1
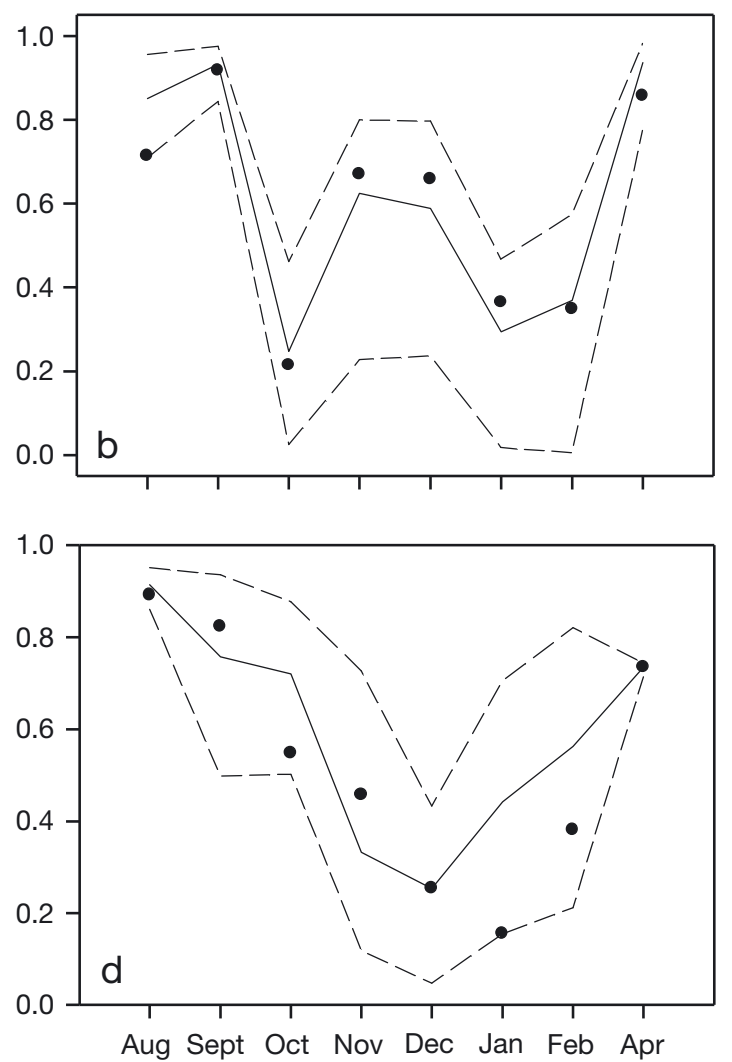

Fig. 5. Similarity in distribution of successful and unsuccessful black-legged kittiwake Rissa tridactyla breeders in 2009 from (a) Grumant, (b) Hornøya, (c) Røst and (d) Rathlin within the core areas used (50\% kernel contours) in the subsequent winter. Similarity was assessed using Bhattacharyya's affinity measure (Fieberg \& Kochanny 2005): shown are observed values (filled circles) and median (solid line), 2.5 and 97.5 percentiles (dashed lines) from randomised permutation (see 'Materials and methods' for details) 
of the SW colonies (Rathlin, Fig. $6 \mathrm{~g}$ ). In the remaining 2 SW colonies (Hafnarhólmi, Fig. 6e; Isle of May, Fig. 6f), overlap in utilisation distributions of successful and unsuccessful individuals was high in the summer and following spring, moderate in mid-winter
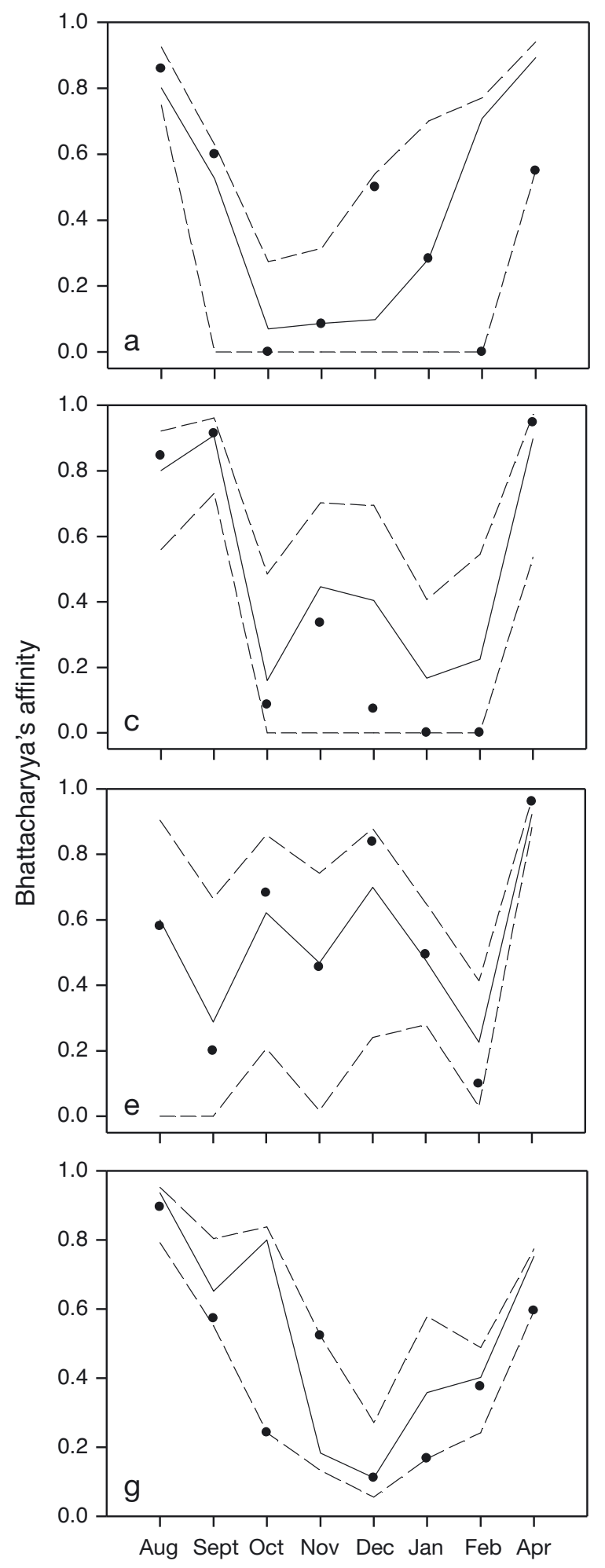

and low to moderate during migration (September to October and February; Fig. 6). Monthly overlap in distribution of the 2 groups of breeders did not deviate significantly from that expected by chance for any of the colonies, although the observed values
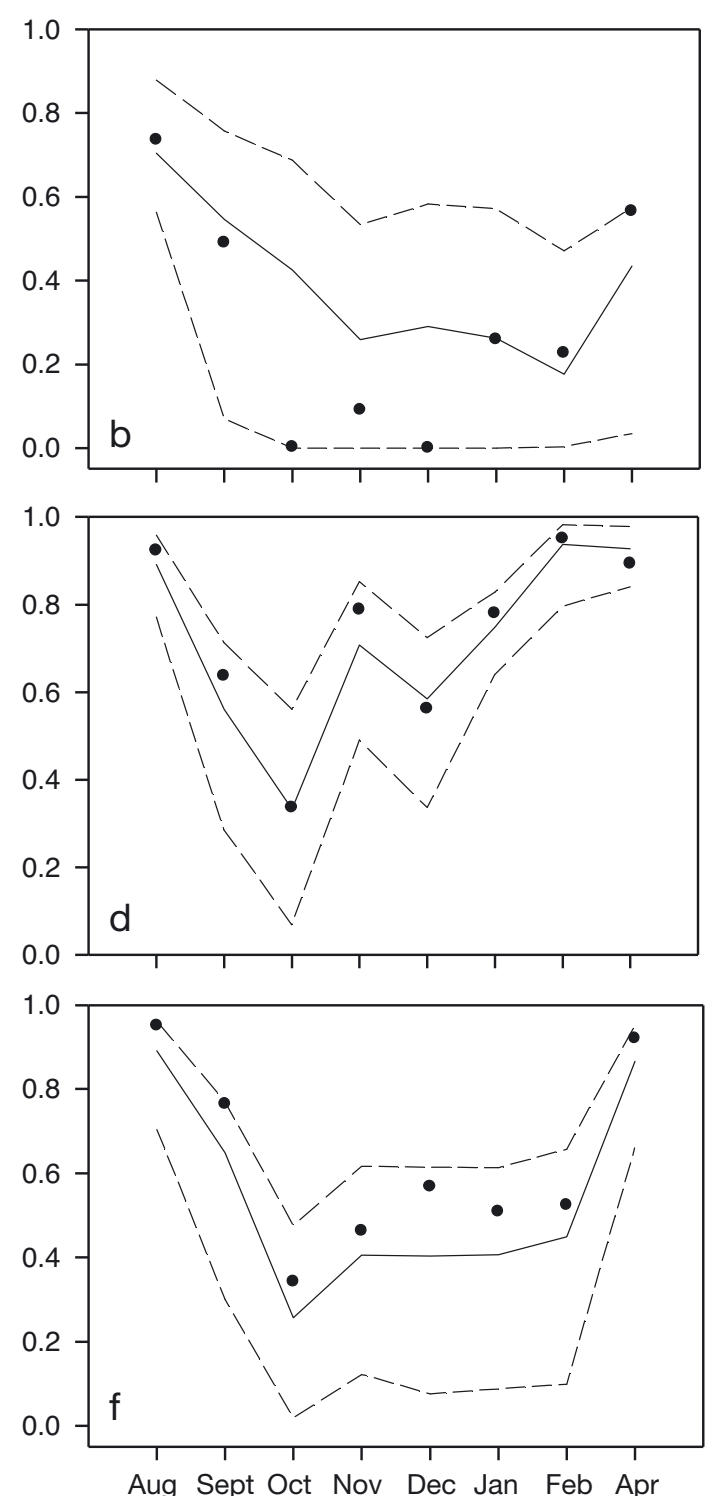

Fig. 6. As in Fig. 5, but for the similarity in distribution of successful and unsuccessful black-legged kittiwakes Rissa tridactyla breeders in 2010 from (a) Anda, (b) Grumant, (c) Hornøya, (d) Røst, (e) Hafnarhólmi, (f) Isle of May and (g) Rathlin within the core areas used (50\% kernel contours) in the previous winter 
(particularly for NE colonies) fell close to or at the 2.5 percentile of the permutation distribution during much of the winter (Fig. 6).

\section{DISCUSSION}

To our knowledge, this study is the first to test for individual carry-over effects across more than 2 seasons in multiple populations. We found strong evidence of spatio-temporal variation in the strength of carry-over effects between breeding success and winter migration. Effects of breeding success on migratory movements weakened over the course of the winter, and by the time individuals arrived back at the colony the following year, differences between previously successful and unsuccessful individuals had disappeared. Furthermore, these links between breeding success and subsequent winter migration patterns were only apparent at colonies in the southwest of the study region; no effect was discernible in kittiwakes at Norwegian colonies. In contrast, effects of winter migration on subsequent breeding success were much weaker, and there was no evidence of any association with breeding success in the previous year; instead, breeding success was predominantly associated with colony identity. Winter distribution was not associated with breeding success in the previous or following summer, suggesting that seasonal interactions were most strongly linked to timing of migration, rather than winter destination. Our results suggest that the strength of carry-over effects shows considerable structure across space and time, with potentially important consequences for meta-population dynamics.

We found partial support for our first hypothesis, that there would be an overall relationship between breeding success and scheduling and location of migration. Thus, unsuccessful individuals departed the colony earlier and, for some colonies, reached their winter destination sooner and spent longer at those destinations, in line with previous findings (Summers et al. 1996, Phillips et al. 2005, 2007, Bogdanova et al. 2011). However, our study contrasted with previous work on 1 study population (on the Isle of May), which found a relationship between breeding success and subsequent winter destination, with unsuccessful individuals typically migrating to the NW Atlantic and successful individuals to the northeast Atlantic or North Sea (Bogdanova et al. 2011). However, in the present study, which was based on data collected 2 yr later, there was no evidence of spatial segregation, and the majority of successful and unsuccessful individuals wintered in the northwest Atlantic. Such contrasting downstream consequences of breeding outcome among years at the same colony may be linked to differences in prevailing conditions, such that carry-over effects are stronger when conditions are less favourable (Legagneux et al. 2012, Harrison et al. 2013). Thus, conditions may have been poorer in the season preceding the winter when there were effects on destination. In support of this, breeding success was significantly lower on the Isle of May than in the season before effects were apparent on migration schedules ( 0.24 vs. 1.36 chicks fledged per pair).

We found support for our second hypothesis, that there would be spatial variation in the strength of carry-over effects among colonies. We found marked spatial variation in the links between breeding success and winter migration, such that, with the exception of timing of colony departure, positive associations were only found in individuals from SW colonies. Most individuals from both colony clusters spent time in a post-breeding area before migrating to their main wintering area. Individuals from the NE colonies moved to the Barents Sea, a highly productive area close to their colonies (Jakobsen \& Ozhigin 2011). They remained there until late autumn when constant darkness and ice cover may have made conditions unfavourable for foraging. In contrast, many individuals from SW colonies moved to the North Sea or Denmark Strait, which are also known to be highly productive in late summer (Paramor et al. 2009, Pálsson et al. 2012), departing for their main wintering area before kittiwakes from NE colonies. Breeding success may have a differing effect on migration schedules in different regions because of variation in prevailing environmental conditions. Oceanographic features such as sea temperature anomalies and primary productivity are important drivers of prey distribution and abundance and are therefore key characteristics of the foraging habitats of marine top predators, including seabirds (e.g. Block et al. 2011). If foraging conditions in the Barents Sea are more favourable than in other regions, any difference between successful and unsuccessful individuals may disappear. Conditions at SW colonies may be less favourable since they lie closer to the edge of the species' range. These regional differences could operate via a similar mechanism whereby environmental conditions determine interannual variation in strength of carry-over effects in single populations (Legagneux et al. 2012, Harrison et al. 2013). This assertion is supported by the substantially later migration from the post-breeding area of individuals 
from NE colonies, and the lower proportion of the population that migrated directly to the main wintering area compared with SW colonies.

The effect of breeding success on migration in SW colonies weakened over the course of the winter in this study, and this pattern was also apparent in previous results from the Isle of May (Bogdanova et al. 2011). Furthermore, there was only limited evidence of an effect of timing of migration on subsequent breeding success, and no evidence that these effects varied across the region. Moreover, there was no evidence that breeding success in the second year was related to success in the previous year. Instead, there was a strong effect of colony identity on breeding success, suggesting that productivity was sensitive to prevailing, local conditions, in line with many previous studies (Clutton-Brock 1988, Newton 1989), and these may potentially have overridden any carryover effects from the previous winter.

Establishing whether seasonal interactions result from genuine carry-over effects, whereby events or processes in one season have causal effects on subsequent seasons, or cross-seasonal correlations due to stable within-individual performance, is challenging. Powerful approaches exist, in particular manipulative experiments (Studds \& Marra 2005, Legagneux et al. 2012, Catry et al. 2013, Schultner et al. 2014) or long-term longitudinal measurements whereby individuals act as their own controls (Daunt et al. 2014). Our approach to investigating the temporal structure in the strength of carry-over effects at multiple colonies provides an additional method of distinguishing between genuine carry-over effects and crossseasonal correlations (our third hypothesis). The weakening of seasonal interactions over time found consistently across multiple colonies indicates that genuine carry-over effects were likely operating between summer and winter in kittiwakes in the North Atlantic (Hypothesis 3a). Had we found a sustained strength of seasonal interaction across the full annual cycle, a more likely explanation would have been consistent performance within individuals associated with intrinsic ability (Hypothesis 3b). Withinindividual consistency coupled with among-individual variation could result from effects of age and experience on breeding success and winter migration. Although our data provide support for true carryover effects, we cannot discount the possibility that intrinsic effects also partially underpinned the links between breeding success and subsequent migratory movements (Daunt et al. 2006, 2014).

Our analysis only included individuals that made a breeding attempt in 2010 and thus excluded any individuals skipping breeding in that year. This restriction could be important since skipped breeding may not be evenly distributed across groups (Cam et al. 1998) and not including this effect could therefore lead to a bias in the results. However, there was no clear indication of significant non-breeding, i.e. individuals holding sites but not breeding, which is what generally happens in this species (as opposed to individuals being completely absent from the colony for the breeding season; Harris \& Wanless 1997). Other potential sampling issues that could have biased our results include cases where individuals were not recaptured in 2010 because they had re-located to inaccessible parts of the study colonies, since breeding dispersal is known to occur in this species, typically associated with breeding failure (Boulinier et al. 2008, Ponchon et al. 2015). However, at the colonies, researchers carried out searches for individuals carrying loggers well outside the location where deployments took place. In addition, site fidelity was high at all colonies and thus few breeding attempts resulting from re-location are likely to have been missed. The study was also unable to quantify rates of partner change between 2009 and 2010, a potentially important determinant of change in breeding success (Black 1996). Incorporating partner change might have helped explain some of the variation in breeding success in 2010 and therefore improved our ability to detect carry-over effects.

Quantifying the strength of downstream fitness effects arising from seasonal interactions is a crucial goal in population ecology. There is now strong evidence that carry-over effects are widespread in nature, but what is less clear is the extent to which they vary temporally and spatially. Our study provides evidence for a decay in strength over time and marked spatial variation in seasonal interactions, and also indicates that the effects of breeding success on subsequent winter migration are much stronger than the effects of migration on subsequent breeding. These complex dynamics are likely to have important consequences for range-wide population dynamics, since carry-over effects have the potential to explain a considerable amount of variation in individual fitness (Norris \& Marra 2007, Harrison et al. 2011). The precise spatio-temporal structure of these links will determine which seasonal conditions are most important and which demographic rates and regions are most affected. If the patterns recorded here are consistent across years, the population dynamic consequences of carry-over effects are likely to occur primarily in the south-western part of the range, mediated by conditions during the breeding season 
affecting over-winter survival probability. Associated geographic variation in population trajectories could, ultimately, lead to species range shifts. To achieve a comprehensive understanding of these fitness consequences, an important future priority is therefore to investigate to what extent the spatial variation in seasonal interactions recorded in this study is consistent across years. An additional priority for future research is to quantify spatio-temporal variation in carry-over effects on demographic rates that we could not consider here, notably survival, breeding propensity and dispersal (Boulinier et al. 2008, Reiertsen et al. 2014). Furthermore, given their potential to drive both temporal and spatial variation in the strength of carry-over effects, investigating the role of environmental conditions should be a key consideration for future studies.

Acknowledgements. We are very grateful to the numerous people involved in field data collection, in particular Jacob González-Solís, David Grémillet, Aurore Ponchon, Jérémy Tornos and Rob Barrett. The work was funded by the Natural Environment Research Council (UK), Northern Ireland Environment Agency, Shetland Oil Terminal Environmental Advisory Group, Fram Centre (Norway), Norwegian Environment Agency (formerly Directorate for Nature Management), Norwegian SEAPOP Programme and French Polar Institute (IPEV programme no. 333). Procedures were conducted under licences and ethical guidelines relevant to all countries involved.

\section{LITERATURE CITED}

Bartoń K (2015) MuMIn: multi-model inference, R package version 1.14.0. https://cran.r-project.org/web/packages/ MuMIn/

Bates D, Maechler M, Bolker B, Walker S (2015) Fitting linear mixed-effects models using lme4. J Stat Softw 67:1-48

* Bearhop S, Hilton GM, Votier SC, Waldron S (2004) Stable isotope ratios indicate that body condition in migrating passerines is influenced by winter habitat. Proc R Soc B 271:S215-S218

Black JM (1996) Partnerships in birds: the study of monogamy. Oxford University Press, New York, NY

Block BA, Jonsen ID, Jorgensen SJ, Winship AJ and others (2011) Tracking apex marine predator movements in a dynamic ocean. Nature 475:86-90

Bogdanova MI, Daunt F, Newell MA, Phillips RA, Harris MP, Wanless S (2011) Seasonal interactions in the blacklegged kittiwake Rissa tridactyla: links between breeding performance and winter distribution. Proc R Soc B 278:2412-2418

Boulinier T, McCoy KD, Yoccoz NG, Gasparini J, Tveraa T (2008) Public information affects breeding dispersal in a colonial bird: kittiwakes cue on neighbours. Biol Lett 4: 538-540

Burnham KP, Anderson DR (2002) Model selection and multimodel inference: a practical information-theoretic approach. Springer-Verlag, New York, NY
Calenge C (2006) The package 'adehabitat' for the R software: a tool for the analysis of space and habitat use by animals. Ecol Model 197:516-519

Cam E, Hines JE, Monnat JY, Nichols JD, Danchin E (1998) Are adult nonbreeders prudent parents? The kittiwake model. Ecology 79:2917-2930

* Catry P, Dias MP, Phillips RA, Granadeiro JP (2013) Carryover effects from breeding modulate the annual cycle of a long-distance migrant: an experimental demonstration. Ecology 94:1230-1235

Clutton-Brock TH (ed) (1988) Reproductive success. Studies of individual variation in contrasting breeding systems. University of Chicago Press, Chicago, IL

* Daunt F, Afanasyev V, Silk JRD, Wanless S (2006) Extrinsic and intrinsic determinants of winter foraging and breeding phenology in a temperate seabird. Behav Ecol Sociobiol 59:381-388

W Daunt F, Reed TR, Newell M, Burthe S, Phillips RA, Lewis S, Wanless S (2014) Longitudinal bio-logging reveals interplay between extrinsic and intrinsic carry-over effects in a long-lived vertebrate. Ecology 95:2077-2083

* Fieberg J, Kochanny CO (2005) Quantifying home-range overlap: the importance of the utilization distribution. J Wildl Manag 69:1346-1359

*Frederiksen M, Moe B, Daunt F, Phillips RA and others (2012) Multi-colony tracking reveals the winter distribution of a pelagic seabird on an ocean basin scale. Divers Distrib 18:530-542

* Gasparini J, McCoy KD, Tveraa T, Boulinier T (2002) Related concentrations of specific immunoglobulins against the Lyme disease agent Borrelia burgdorferi sensu lato in eggs, young and adults of the kittiwake (Rissa tridactyla). Ecol Lett 5:519-524

*Griffiths R, Daan S, Dijkstra C (1996) Sex identification in birds using two CHD genes. Proc R Soc B 263:1251-1256

*Harris MP, Wanless S (1997) Breeding success, diet, and brood neglect in the kittiwake (Rissa tridactyla) over an 11-year period. ICES J Mar Sci 54:615-623

*Harrison XA, Blount JD, Inger R, Norris DR, Bearhop S (2011) Carry-over effects as drivers of fitness differences in animals. J Anim Ecol 80:4-18

* Harrison XA, Hodgson DJ, Inger R, Colhoun K and others (2013) Environmental conditions during breeding modify the strength of mass-dependent carry-over effects in a migratory bird. PLOS ONE 8:e77783

*Hoye BJ, Hahn S, Nolet BA, Klaassen M (2012) Habitat use throughout migration: linking individual consistency, prior breeding success and future breeding potential. J Anim Ecol 81:657-666

Inger R, Harrison XA, Ruxton GD, Newton J and others (2010) Carry-over effects reveal reproductive costs in a long-distance migrant. J Anim Ecol 79:974-982

Jakobsen T, Ozhigin VK (eds) (2011) The Barents Sea. Ecosystem, resources, management. Half a century of Russian-Norwegian cooperation. Tapir Academic Press, Trondheim

*Latta SC, Cabezas S, Mejia DA, Paulino MM, Almote H, Miller-Butterworth CM, Bortolotti GR (2016) Carry-over effects provide linkages across the annual cycle of a Neotropical migratory bird, the Louisiana waterthrush Parkesia motacilla. Ibis 158:395-406

炎Legagneux P, Fast PLF, Gauthier G, Bety J (2012) Manipulating individual state during migration provides evidence for carry-over effects modulated by environmental conditions. Proc R Soc B 279:876-883 
Lewis S, Wanless S, Wright PJ, Harris MP, Bull J, Elston DA (2001) Diet and breeding performance of black-legged kittiwakes Rissa tridactyla at a North Sea colony. Mar Ecol Prog Ser 221:277-284

Lindström J (1999) Early development and fitness in birds and mammals. Trends Ecol Evol 14:343-348

Marra PP, Hobson KA, Holmes RT (1998) Linking winter and summer events in a migratory bird by using stablecarbon isotopes. Science 282:1884-1886

Metcalfe NB, Monaghan P (2001) Compensation for a bad start: grow now, pay later? Trends Ecol Evol 16:254-260

Nakagawa S, Schielzeth H (2013) A general and simple method for obtaining $\mathrm{R}^{2}$ from generalized linear mixedeffects models. Methods Ecol Evol 4:133-142

Newton I (ed) (1989) Lifetime reproduction in birds. Academic Press, London

Norris DR, Marra PP (2007) Seasonal interactions, habitat quality, and population dynamics in migratory birds. Condor 109:535-547

Norris DR, Marra PP, Kyser TK, Sherry TW, Ratcliffe LM (2004) Tropical winter habitat limits reproductive success on the temperate breeding grounds in a migratory bird. Proc R Soc B 271:59-64

Pálsson ÓK, Gíslason A, Guðfinnsson HG, Gunnarsson B and others (2012) Ecosystem structure in the Iceland Sea and recent changes to the capelin (Mallotus villosus) population. ICES J Mar Sci 69:1242-1254

Paramor OAL, Allen KA, Aanesen M, Armstrong C and others (2009) MEFEPO North Sea Atlas. University of Liverpool

Phillips RA, Silk JRD, Croxall JP, Afanasyev V, Briggs DR (2004) Accuracy of geolocation estimates for flying seabirds. Mar Ecol Prog Ser 266:265-272

Phillips RA, Silk JRD, Croxall JP, Afanasyev V, Bennett VJ (2005) Summer distribution and migration of nonbreeding albatrosses: individual consistencies and implications for conservation. Ecology 86:2386-2396

Phillips RA, Catry P, Silk JRD, Bearhop S, McGill R, Afanasyev V, Strange IJ (2007) Movements, winter distribution and activity patterns of Falkland and brown skuas: insights from loggers and isotopes. Mar Ecol Prog Ser 345:281-291

Editorial responsibility: Rory Wilson,

Swansea, UK
Pinheiro J, Bates D, DebRoy S, Sarkar D, R Core Team (2016) nlme: linear and nonlinear mixed effects models. R package version 3.1-128. http://CRAN.R-project.org/ package $=$ nlme

* Ponchon A, Chambert T, Lobato E, Tveraa T, Gremillet D, Boulinier $T$ (2015) Breeding failure induces large scale prospecting movements in the black-legged kittiwake. J Exp Mar Biol Ecol 473:138-145

R Core Team (2015) R: a language and environment for statistical computing. R Foundation for Statistical Computing, Vienna

Reiertsen TK, Erikstad KE, Anker-Nielssen T, Barrett RT and others (2014) Prey density in non-breeding areas affects adult survival of black-legged kittiwakes Rissa tridactyla. Mar Ecol Prog Ser 509:289-302

Schultner J, Moe B, Chastel O, Tartu S, Bech C, Kitaysky AS (2014) Corticosterone mediates carry-over effects between breeding and migration in the kittiwake Rissa tridactlya. Mar Ecol Prog Ser 496:125-133

Senner NR, Hochachka WM, Fox JW, Afanasyev V (2014) An exception to the rule: carry-over effects do not accumulate in a long-distance migratory bird. PLOS ONE 9: e86588

Sorensen MC, Hipfner JM, Kyser TK, Norris DR (2009) Carry-over effects in a Pacific seabird: stable isotope evidence that pre-breeding diet quality influences reproductive success. J Anim Ecol 78:460-467

Stearns SC (1992) The evolution of life histories. Oxford University Press, New York, NY

* Studds CE, Marra PP (2005) Nonbreeding habitat occupancy and population processes: an upgrade experiment with a migratory bird. Ecology 86:2380-2385

Summers RW, Underhill LG, Howells RJ, Vickery JA, PrysJones RP (1996) Phenology of migration and use of wintering sites by the increasing population of dark-bellied brent geese Branta bernicla bernicla. J Zool (Lond) 239: 197-208

Ylönen H, Sinervo B, Smith H (eds) (1998) Costs of reproduction. Oikos 83(Spec Issue):417-584

Zuur AF, Ieno EN, Walker NJ, Saveliev AA, Smith GM (2009) Mixed effects models and extensions in ecology with R. Springer, New York, NY

Submitted: July 18, 2016; Accepted: February 13, 2017

Proofs received from author(s): April 9, 2017 